Research Article

\title{
Practices and Processes in BIM Projects: An Exploratory Case Study
}

\author{
Conrad Boton (iD) and Daniel Forgues \\ Department of Construction Engineering, Ecole de Technologie Supérieure, Montreal, Canada \\ Correspondence should be addressed to Conrad Boton; conrad.boton@etsmtl.ca
}

Received 5 May 2018; Revised 1 July 2018; Accepted 10 July 2018; Published 6 August 2018

Academic Editor: Eric Lui

Copyright (C) 2018 Conrad Boton and Daniel Forgues. This is an open access article distributed under the Creative Commons Attribution License, which permits unrestricted use, distribution, and reproduction in any medium, provided the original work is properly cited.

\begin{abstract}
The results of an exploratory case study dedicated to a BIM project are presented and the perception that professionals have of their practices and the BIM collaboration processes is discussed in this study. It suggests that the roles of BIM specialists are not the same from one discipline to another and that they are not just technical roles. In addition, the information subprocess seems to crystallize around BIM managers, which tends to create two sources of leadership in a project: BIM managers and project managers. Finally, the study shows a gap between the planned processes and those actually used in the project. The use of a big room, to bring together the owner and the other disciplines, seems to be particularly useful. It serves as an integrator, and information is better shared.
\end{abstract}

\section{Introduction}

The building information modeling (BIM) approach is dramatically changing the way projects are managed in architecture, engineering, and construction. The BIM approach's recent technological developments are full of promises. By providing a three-dimensional model as a central component of construction projects, BIM gives the construction industry the tools it needs to better manage its duality of process and product [1]. The model of the product can, therefore, be more finely analyzed upstream in order to both open up the design process and fine-tune the construction.

With the increasing success of the BIM approach, construction management practices are evolving, showing more clearly the limitations of the current theories [2-4]. Indeed, the use of three-dimensional models as the main database and vector of exchange during the life cycle of the building greatly not only improves [5] but also increases $[6,7]$ the need for integration in the supply chain and the information sharing. Moreover, with the success of the BIM approach, the vision of the project is no longer limited to the facility's beginning of life but extends to its whole life cycle, including its operation [8] and its end of life [9]. Thus, client requirements are no longer limited to functionality or quality requirements [10] but increasingly incorporate the need to capture during the design and construction phases all the information required for facility management and computer-aided maintenance [11-13]. The gradual capture of this required information and the need to rethink collaboration around the BIM model dramatically changes the information processes in the project. Then, the project manager does not appear to be sufficiently equipped to manage this new information perspective [14] that seems to be taking place in the project and the current core tools seem not sufficient to support his work.

More generally, it becomes important to study the practices in construction projects in the BIM era so as to understand the context in which these changes occur. The changes in practices concern, in particular, the processes put in place that the BIM approach is supposed to modify in a positive way. The establishment of clear and formalized information exchange processes is an important condition for the success of BIM projects [15]. Thus, the process models, as well as the formalisms to represent them equivocally, take an important place in the BIM guides and other protocols. Another aspect of the BIM practices is the use of a common 
physical space (big room) dedicated to the project team. The use of such a common space is supposed to provide the stakeholders with an intensive collaborative work environment that can significantly reduce the decision-making latency [16, 17]. However, many distributed collaboration environments, such as knotworking [16], are proposed as alternatives to big rooms. It becomes important to evaluate to which extent big rooms are helpful for practitioners.

Based on a real BIM implementation exploratory case study, this paper explores how the project and BIM specialists perceive the gap between as-planned BIM implementation and the actual processes used in a fast-track project. The article is organized in three main sections. The first section explores the literature regarding the information flow and collaboration in construction projects and how the actual BIM processes on projects compare to the as-planned ones. This section also examines, from a theoretical perspective, the BIM-related roles in construction projects and how they position in regard to the project managers' role. This literature review is followed by the middle section, which describes the research methodology and then presents the main results of the case study: the managerial roles in the project, the need for all of the project disciplines to share a common physical space, the perceived reliability of the processes proposed in the BIM execution plan, and how the use of BIM could be improved. The paper concludes with a discussion regarding the evolution of the roles of the BIM specialists, how the information subprocess is being crystallized around the BIM manager, and the reliability of the proposed BIM processes for effective collaboration.

\section{Literature Review}

2.1. Information Flow and Collaboration in Construction Projects. Information flow, along with material flow, is one of the two main flows appearing in the typical supply chain in construction industry [18] and corresponds to the subprocess of information identified by Bjork [19]. Even if the information subprocess is less tangible than material subprocess, it is crucial for the success of construction projects because the information is, with material and energy, the third fundamental component of sociotechnical systems [20]. As stated by Winch [14], "the management of construction projects is a problem of information, or rather, a problem in the lack of information required for decisionmaking".

The construction industry, characterized in particular by high fragmentation [21], is considered to have low productivity compared to other comparable industries [22]. Some decades ago, Winch was asking "why the construction of housing and other built products has been so resistant to the virtuous cycle of simultaneous cost reduction and quality improvement that has benefited most other industries over the last century" [23]. One of the main issues in the industry is related to collaboration and information exchange [24]. Indeed, while other discrete manufacturing industries have found a way to optimize their production process in order to achieve optimal results, collaboration in construction remains problematic despite much effort devoted to understanding and improving it. Indeed, an important research effort has been made to improve it in the recent years, notably through the use of information technologies [25-27], including the building information modeling (BIM) approach.

Many case studies reporting BIM-based collaboration experiences have been proposed in the very recent literature. Poirier et al. [28] presented a case study on how BIM impacts collaboration in the construction industry. The main aim of the study was to propose an understanding, based on three motivation elements: the needs for a departure from the predominately positivistic view, the need for a systemic understanding, and the analysis scarcity at the individual level. The results identified five cognitive determinants (requirements, expectations, intentions, incentives, and capabilities), and "the impact of BIM on collaboration is understood as a reshaping of an individual's cognitive determinants, which influence a team member's framing of event patterns enacted throughout project delivery" [28]. Similarly, Liu et al. [29] tried to understand the effects of BIM on collaborative design and construction. They identified eight concepts that have influence on the development of BIM collaboration, including IT capacity, technology management, attitude and behavior, role-taking, trust, communication, leadership, and learning and experience [29]. Mignone et al. [30] relied on a hospital construction case study to evaluate how collaboration in BIM-based construction networks could be enhanced through organizational discontinuity theory. The results include a conceptualization of typical barriers to collaboration in BIM-based construction networks and how to deal with the identified barriers. Kim et al. [31] used the study case of a large-scale construction project to evaluate the value of the construction BIM. Among the findings of the research, the trade contractors were asked how much they think BIM has contributed to their works. The respondents acknowledged the added value of BIM in reducing the average delay of a construction period and the additional construction cost [31]. Merschbrock and Munkvold [32] explored the effective digital collaboration in construction through the case study of a BIM-based hospital construction project. The study identified a set of key factors enabling digital collaboration, including change agents, BIM contracts, a cloud computing infrastructure, and new roles and responsibilities different from the traditional ones [32].

2.2. As-Planned versus Actual BIM Use in Projects. An important particularity of the construction industry lies in its fragmentation and the fact that the various actors involved in construction projects come from different organizations and have to work together temporarily in order to achieve a common objective. Thus, a good collaboration and information exchange are critical for the projects' success but remain challenging in the industry despite many and varied research efforts.

To allow an effective implementation of BIM and to ensure an optimal exchange of information in construction 
projects, various BIM guides have been published. These guides help project team in developing appropriate BIM execution plans (BEPs). It can reasonably be argued that the BIM execution plan represents for the BIM managers what project plan is for project managers. Indeed, "many problems related to uncoordinated collaboration emerge if teams do not develop and sign off on what is commonly known as BIM Execution Plans [...] as early in a project as possible" [33]. The BEP is intended to "orchestrate the entire collaborative process when using BIM" [33]. Various templates have been proposed in order to help BIM managers in drafting effective BEPs. However, the BIM content organization is comparable from a template to another one. Typically, a BEP contains the following:

(1 )The project information, including the project goals, delivery strategy and milestones, and the BIM uses and deliverables

(2) the BIM resources and planning, including the model structure, the technological infrastructure, and the structure, schedule, and delivery of BIM models

(3) the collaboration and information exchanges, including the collaboration procedures, the staffing and roles, the key contacts, the information exchange protocols, and formats

However, as stated by Holzer, the use of BEP "has not yet become standard on all medium- to large-scale construction projects" [33]. A study conducted by Eadie et al. [34] showed that while BIM execution plans have been extensively used to support BIM use at all the project stages, its perceived benefits have been realized by less than $50 \%$ of the users. Moreover, a large proportion of the practitioners report an average gap between the planned BIM processes and the actual BIM processes used in the project.

Having a deviation between the as-planned processes and the actual ones is not unusual in the construction industry. de Blois et al. [35] have shown how significant differences may exist between as-planned processes and the actual ones, and how the traditional linear processes are overshadowed by iterative ones. The BIM approach is supposed to improve collaboration in the industry, and the BIM underlying processes need to be reliable. The generic linear processes proposed in the BIM execution plans and guidelines seem to not be adapted to some complex projects like the one described in this study. For example, in the case study, the practitioners consider that the proposed processes are too obvious, not detailed enough, and too linear to be used as is, especially for fasttrack projects, one of the advantages of the research recently presented by de Blois et al. [35] lies in the systemic approach theories that they refer to in order to address the complexity of the interaction among project structures and processes. Similarly, the BIM approach could benefit from a better understanding of the systemic nature of the construction industry in order to improve collaboration processes. Current trends for improving construction collaboration are based on good practices from other industries such as aerospace and automotive. Meanwhile, utilizing the systemic approach to address the construction industry has been advocated by various researchers $[1,28,36]$.

2.3. Big Room in BIM Practices. The "Big Room" concept comes from lean construction theories and consists of bringing "together cross-functional teams under one roof to explore problems" [37]. In the context of BIM projects, Kerosuo et al. [16] consider big rooms as "one application of IPD that has been created in large healthcare projects in the US" in order to allow designers to "work side by side in the same place in order to share information with each other in a better way than working separately in different design offices" [16]. Indeed, big rooms can be very helpful in facilitating the collaboration processes involving the project stakeholders working in the same room [38]. In such environments, it is possible to collaboratively "refine the design" by using a wide-ranging list of possibilities, in order to achieve the objectives of the projects with a good level of confidence [38]. In the integrated design process, the degree of confidence seems particularly high for establishing costs and budgets at feasibility phase, defining construction method and selecting building systems at conceptual design phase, for producing time schedule, determining management team and structure, and carrying out risk assessment at both conceptual and preliminary design phases and for assessing workflow patterns, determining major mechanical equipment, establishing the control systems, and defining site layout at the detailed design phase [38].

Big rooms are more and more used to improve BIMbased collaboration in construction. Applied to BIM projects, big rooms provide similar benefits and appear to be more economical by allowing an effective coordination of the design work in a shared space [16]. However, it has been noted that it is challenging to implement on small construction projects and more adapted to large construction project [16]. Thus, some innovative collaboration practices are emerging, including knotworking, a novel-distributed collaborative practice, to better support collaboration in smaller BIM-based projects [16]. Kerosuo et al. [16] presented a comparison between big room and knotworking approaches and concluded that "full-time commitment to a Big Room collaboration in a single project may be difficult" for practitioners in Finland where "some construction projects are customarily smaller". While this applies to the Finnish construction industry, it seems necessary to evaluate if it is the case in other contexts.

\subsection{The Traditional Role of a Project Manager. A project} manager's role is crucial, and his or her competence is seen as "clearly a vital factor in the success of a project" [39]. Moreover, the main failure factors identified for project management include "the wrong person as project manager" [40]. Kerzner [41] stated that "the major factor for the successful implementation of project management is that the project manager and team become the focal point of integrative responsibility." According to Cooper [42], the 
basic business of a project manager is to deliver an end product that is compliant with performance requirements and within the budget and time limitations specified by the customer. The generic responsibilities of the project manager include defining the work's requirements, establishing the work's extent, allocating the required resources, planning the activities' execution, monitoring the work progress, and adjusting possible deviations [40].

Since projects generally involve professional specialists from different disciplines, the role of the project manager is also seen as an integrator with relationship management responsibilities [43]. Project managers are then considered as integrators whose aim is to achieve a "unity of effort among the major functional specialists" [44]. As an integrator, the project manager has to accommodate personal goals with the global objectives and to ensure a good team integration as well as consistent and efficient information flow.

New roles, such as BIM managers, are emerging in the construction projects in order to complement the project managers. Similarly to the Project Management Body Of Knowledge (PMBOK) Guide [45], some BIM execution plan (BEP) guides are also appearing in order help BIM managers in their job, by providing guidelines and processes [46-48]. But it seems that the responsibilities of BIM managers, only technical in the past, seem to have evolved into more managerial responsibilities [49]. And it is important to evaluate how both project managers and BIM managers position themselves in relation to the generic processes proposed in the BEPs.

\subsection{The Emerging Roles of BIM Managers, Coordinators, and} Champions. Assuming that the changes induced by the implementation of information and communication technologies such as BIM are not purely technical, Froese [50] stated that changes to management processes are necessary. Indeed, BIM can be a "catalyst for Project Managers to reengineer their processes to better integrate the different stakeholders involved in modern construction projects" [51]. Froese [50] identified three main types of impact on construction project management, including (1) the need to explicitly manage project information and information systems; (2) the need to recognize, to represent, and to more explicitly manage the interdependencies due to the high degree of integration and collaboration across the tasks of a project; and (3) the need for the project team to recourse together to full virtual prototypes "as the central activity for the design and management of the project".

According to Froese [50], the fundamental changes are then prompted by the fact that the project team members need to collaborate, using computer-based tools, to produce comprehensive "virtual prototypes of all aspects of a construction project as the central activity for the design and management of the project" [50]. The distance between technical competencies and management functions in a project must then be considerably reduced; and consequently, managers need to be closer to the virtual prototypes. In February 2013 issue, AEC Magazine stated that the changes made by BIM are so important that it is utopian to think that a computer-aided design (CAD) manager alone can coordinate its implementation in a firm [52]. Instead, there must be support from the senior hierarchy as well as a practical method for change management. Managing BIM involves different levels of responsibility and technical expertise that require new roles not only in the use of technology and modeling standards but also in the coordination of BIM implementation contexts [53].

Barison and Santos [53] have tried to inventory the new roles and responsibilities that are coming with BIM. An interesting outcome from their work is that these roles are not simply related to technical competencies but they also involve integration and leadership-related aspects. Boton et al. [54] proposed a distribution of the weights of BIMspecific knowledge expected for different BIM specialists (Figure 1). Based on previous related works, they identified the BIM manager, the BIM analyst, the BIM modeler or operator, the BIM facilitator, and so on.

Davies et al. [49] proposed a review of the definitions proposed in various BIM guides and standards on the BIM specialist roles. This very interesting work showed significant outcomes including how these roles are being developed in an "uncoordinated manner." Specifically, the work showed "a lack of definition of client-side roles in the BIM process, the inclusion of organizational BIM roles and activities in project-level guides and standards, and overlapping use of similar role titles to describe different functions within BIM project teams." But, according to Davies et al. [49], all these roles can be categorized into four major groups: two project roles (project BIM manager and BIM coordinator) and two organizational roles (BIM modeler and internal BIM manager).

2.6. The Theoretical Role of the BIM Manager. One of the most often cited new roles is that of the BIM manager, who is far from a simple substitution of the usual CAD manager [52]. The BIM manager's role is the most commonly mentioned in the literature. Compared to other BIM-related roles, it has been extensively described in the existing BIM guides and protocols [49]. However, according to Holzer, it is challenging to describe what BIM managers do because it is a role in transition [33]. Indeed, "What was once associated with responsibilities for overseeing BIM model development is now more and more associated with information management, change facilitation, process planning, technology strategies, and more" [33]. Thus, Barison and Santos [53] stated that "the main function of a BIM Manager is to manage people in the implementation and/or maintenance of the BIM process" [53]. While this definition seems interesting, it is important to distinguish the project role of BIM managers from their organizational role [49].

In his project role, the BIM manager is responsible to develop and deliver the BIM execution plan and to establish the project's BIM protocols. He is also responsible for the quality insurance, the BIM project meetings' preparation, and the project records management [49]. The BIM 


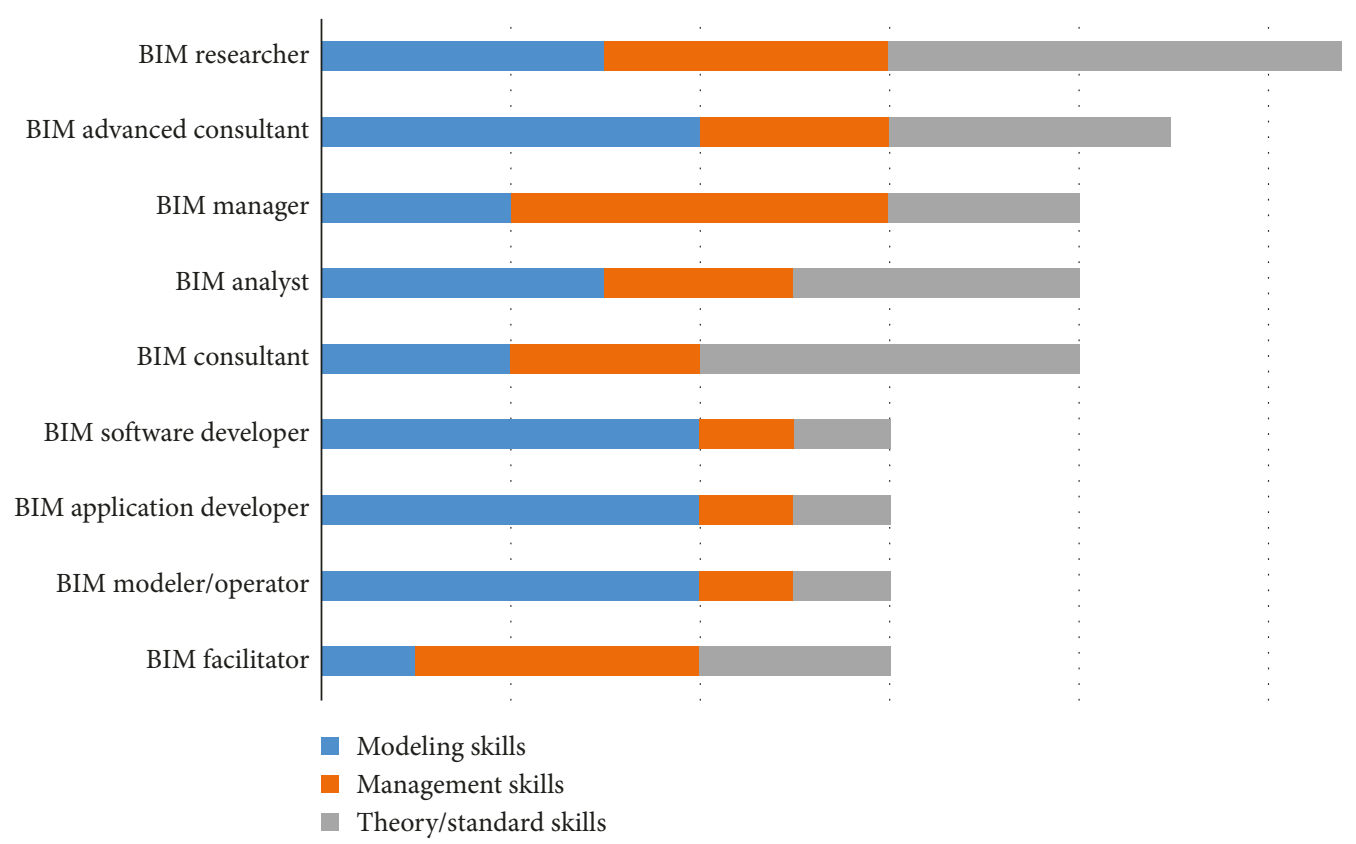

FIgUre 1: A distribution of the weights of BIM-specific knowledge expected for different BIM specialists [54].

manager's organizational role depends on the "size and characteristic of an organization" [33]. In smaller companies, it can combine, at the same time, different roles including BIM modeler and project architect [33]. More generally, he is often the BIM representative of the specific discipline (BIM coordinator) [49]. It is then "not uncommon for the same individual to undertake project and organizational tasks".

In terms of degree of authority, in many BIM guides, "the BIM Manager role is the overarching project role" while in other documents, he is "expected to report to the Project Manager who has the oversight role" [49]. According to Holzer, "there is likely to be a time where BIM Managers become obsolete and their responsibilities will become part of project management in general" [33]. However, it is not clear yet how these roles coexist in the real-life context. To fully understand the different roles and the related challenges in the current BIM practices, it seems necessary to go further the theoretical works presented above and to analyze a real representative project in which the different roles are involved.

\section{Research Methodology}

3.1. Research Approach: Exploratory Case Study. According to Gerring [55], a case study is "an intensive study of a single unit for the purpose of understanding a larger class of (similar) units." Case studies are more generally defined as empirical and offer a rich description of a phenomenon in particular instances, typically based on a variety of data sources [56]. Theoretical propositions and constructs can be created by using case-based evidence [57]. The case study method can use both quantitative and qualitative evidence [33]. This information can come from observations, verbal records, and fieldwork, with multiple data collection methods including ethnographies and participantobservation, [58]. Case studies thus represent a research strategy [58], and the case study method is then defined as a "way of defining cases, not a way of analyzing cases or a way of modeling causal relations" [55]. This approach is distinguished from other methods by its reliance "on covariation demonstrated by a single unit and its attempt, at the same time, to illuminate features of a broader set of units" [55]. One of the most practical results of case studies is their use in forming descriptive inferences [55]. The case study might be descriptive, explanatory, or exploratory [59].

The exploratory case study aims at extending the understanding of social phenomena that are considered as complex [60]. It is used as "a sound and sensible first step" when extensive empirical research has not been yet dedicated to the topic of interest [60]. The use of such an approach may be justified when the terrain is little known or stereotyped views are imposed [61] In these cases, it is possible to "better define a problem, suggest hypotheses to be checked later, generate ideas for new services, collect reactions on an emerging concept, or pretest a questionnaire" [61]. This approach is not based solely on assumptions and is generally flexible and not rigid structured [61]. The aim of the study reported in this paper is not to generate final or definitive evidence but to suggest some hypotheses to be checked later, in future works.

3.2. Data Collection. The exploratory case study presented in this section is related to the expansion of a Canadian airport, and the main aim was to study how BIM has been implemented in the project. It was conducted during the first half of 2015 while the project was still in the design stage. The research approach is based on four major data collection 
tools: review of project documentation, survey, semistructured interview, and observation.

The first step of the research consists of a review of the project documents the project team made available to the researchers. The reviewed documents include the project's BIM execution plan, the project organization chart, the appendices dedicated to the BIM processes, and the appendices related to the profiles of the BIM stakeholders. Some other documents related to the BIM modeling activities have also been reviewed by the researchers. These documents include the BIM objects organization tree and nomenclature, the file transfer protocol, the clashes and interferences management process, the quality control plan, generator of conflict spheres guide, the BCF-based collaborative communication process, the LOD specifications file, the CODEBOOK tutorial, and the data transfer tool guide.

The second step of the research consists of an online survey to capture and understand the perception and opinions of the project's stakeholders. Indeed, the project documentation made it possible to understand the BIM practices as planned, but the survey not only brought in more details, it also and especially made it possible to understand the actual practices of the project as perceived by the actors involved. In addition to the general issues, the survey consisted of three parts, corresponding to the three dimensions generally used to study the implementation of BIM: technology, organization, and process. The questionnaire is composed of 56 questions and is built on the SurveyMonkey online system. It is organized into three groups of questions. The first group of questions aims at understanding the profile of the respondent. It is composed of 15 questions including the respondent's specialty, business area, firm and size, the BIM competencies and skills, and the previous experience in using BIM. The second group of questions is dedicated to the use of BIM in the studied project. This includes the proportion of the dedicated to BIM in the project, the evaluation of the use of BIM in the project, the client involvement, the coordination between the stakeholders, the perceived impact of BIM on working methods, and technical questions about the use of specific software (Revit, CodeBook, etc.), and hardware equipment. The third group of questions evaluates the actual use of BIM compared to the as-planned processes and tools. It includes the evaluation, from the practitioners' perspective, of the applicability of the BIM execution plan, the BIM use and data exchange processes, the $3 \mathrm{D}$ coordination mechanisms, the levels of development (LODs) of the BIM models, the means of communication, the inter- and intradisciplinary clash detection processes, and the quality control processes. The questionnaire was only sent to actors involved in this particular project with managerial roles, and a total of 10 responses were received (Figure 2).

Following the online survey, semidirective interviews were then carried out to deepen various aspects of the implementation of BIM in this project. The aim was to confront the project actors with certain inconsistencies between the as-planned practices (from the project documentation) and the actual ones arising from the online survey results. A total of nine people were interviewed.
The topics discussed mainly revolved around the organization of work in the project, the management and the sharing of information in the BIM processes and related challenges, and the potential individual recommendations each interviewee could provide. Table 1 shows the distribution of the interviewees according to their disciplines and roles.

Using ethnographic research methods, the researchers finally observed the project practices and documentation on site for methodological triangulation purposes. The aim of the triangulation is to consolidate the results of the previous steps. With an average duration of one hour, several observations were made over a period of two weeks, according to the methods discussed by Hartmann et al. [62]. The daily work of BIM managers and other BIM-related roles were monitored in order to deepen the mapping of activities related to the BIM process in the project.

3.3. The Studied Case. The business managing firm of a Canadian airport wants to stimulate its growth by expanding its property portfolio. After conducting a market study in 2013 to forecast the attendance at the airport through the next thirty years, the firm estimated that the construction of a new terminal would meet both its needs and those of airlines and future passengers. The long-term goal is to offer long-haul flights to destinations outside Canada. To maximize the growth of the airport, its new infrastructure must meet high requirements in terms of quality and operation. The details of the project are presented in Table 2.

The business management firm decided to implement BIM for this airport expansion project, as they identified the need for improved coordination during the design and construction phases as well as to optimize equipment management through the integration of BIM technology and their current facility management system. Based on both the experience of the owner and the recommendations of a consultant firm, a BIM execution plan was defined, based on the BIM project execution guide proposed by Pennsylvania State University [63]. This plan identifies the project objectives, the priorities, and the related BIM uses, describing the responsibilities and the generic processes to be applied. It is very specific, as it identifies the technological and software environments and the need for exchanges and coordination between the various trades.

Among other goals, the owner's main aim is to successfully implement BIM during the design and the construction phases, as well as to integrate BIM information within its existing facility management system for future purposes. To ensure a good understanding of the challenges, an iterative process was set up to study the project's needs in detail. While this was a very important step, this process induced a significant delay. For this and other reasons, a fasttrack approach was then adopted for the project delivery. In fast tracking, the normal duration of a project may be considerably reduced. A fast-track project is one whose duration can be reduced up to almost $70 \%$ compared to a similar traditional project's duration [64]. 


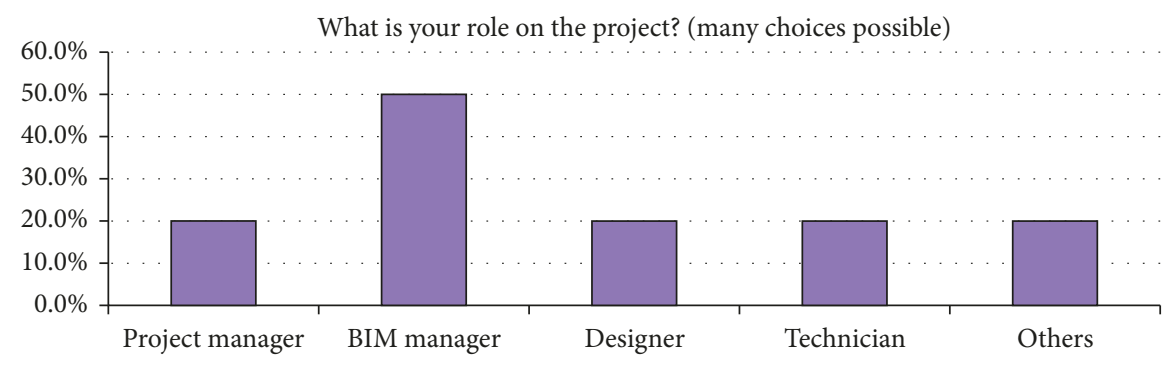

Figure 2: Roles of the respondents to the survey.

TABLE 1: Distribution of interviewees.

\begin{tabular}{lcl}
\hline Disciplines & $\begin{array}{c}\text { Number of } \\
\text { interviewees }\end{array}$ & Roles in the project \\
\hline Architecture & 02 & $\begin{array}{l}\text { (i) BIM manager } \\
\text { (ii) Programme manager }\end{array}$ \\
\hline MEP & 01 & (i) BIM manager \\
Structure & 03 & $\begin{array}{l}\text { (i) BIM manager } \\
\text { (ii) BIM coordinator } \\
\text { (iii) Project manager }\end{array}$ \\
\hline Managing contractor & 02 & $\begin{array}{l}\text { (i) BIM manager } \\
\text { (ii) Project director }\end{array}$ \\
\hline Owner & 01 & (i) BIM manager \\
\hline Total & 09 & \\
\hline
\end{tabular}

\section{The Main Results}

4.1. The Managerial Roles in the Project. The project is managed by a project manager designated by the owner and assisted by external consultants. Five main trades are involved: architecture, structural engineering, civil engineering, MEP (mechanical, electrical, and plumbing) engineering, and general contracting. The firms involved in the project composed a team dedicated to the project; these included, from a theoretical point of view as planned in the project documentation, a project manager and a BIM manager per discipline, except for the general contractor (Figure 3).

In practice, each firm uses its own hierarchy and organization, but the BIM execution plan places a particular emphasis on the responsibilities of the BIM managers. From a theoretical point of view, these responsibilities are mainly related to the management of the models' content, quality control, and 3D coordination. In practice, the architecture firm and the MEP firm have designated dedicated actors (other than the project manager) to hold this role in their organization. The BIM manager designated by the structural engineering firm seems to have a more general role that can be likened to that of a project manager. He is assisted by a BIM coordinator who is responsible for internal BIM model management.

In practice, the BIM managers' roles are not really similar from one discipline to another. The BIM manager designated by the architecture firm has both technical and managerial roles. He is responsible for the weekly upload of the architectural models and their integration with the other models. He defines in advance the elements to be checked for intra- and interdisciplinary clash detection. He also ensures
TABLE 2: Information on the case study.

\begin{tabular}{ll}
\hline Budget & (i) \$277M \\
Delivery method & (i) Fast-track construction \\
management \\
(i) The need to improve coordination \\
during the design and construction \\
phases and to optimize the facility \\
management \\
(ii) The high requirements in terms \\
of quality and operation \\
(iii) The importance of carrying \\
$\begin{array}{l}\text { out the work within extremely } \\
\text { of the project }\end{array}$ & $\begin{array}{l}\text { tight deadlines } \\
\text { (iv) The need to carry out the work in }\end{array}$ \\
& $\begin{array}{l}\text { accordance with the budget forecasts } \\
\text { Existing condition }\end{array}$ \\
$\begin{array}{l}\text { modeling } \\
\begin{array}{l}\text { Design phase } \\
\text { Beginning of the } \\
\text { construction phase }\end{array}\end{array}$ \\
$\begin{array}{l}\text { End of the project as } \\
\text { planned }\end{array}$ & (i) 2014 \\
\hline
\end{tabular}

that each of the designers conducts their internal quality control on the architectural model after working on it during the week.

The MEP firm has a unique hierarchy due to the compounded nature of its business. The designated BIM manager is coupled with a BIM administrator dedicated to each branch (ventilation, electricity, plumbing, etc.) with whom he organizes the work for the whole team. He performs visual inspections of the MEP models. In addition to ensuring that MEP technicians check the quality of their model, he performs the important job of managing and correcting the warnings in the Revit software. The aim is to produce models that have the fewest errors possible.

The BIM manager designated by the structural engineering firm plays a more general role than in the other two disciplines. He works with the project manager to plan and to organize the work to be performed by the structural engineers. He also ensures the quality of the $2 \mathrm{D}$ conceptual rendering provided by his designers, without having any real responsibility for the content of the $3 \mathrm{D}$ models. This role belongs to the BIM coordinator responsible for quality checks on the models. The BIM coordinator role here is quite similar to the BIM manager role in the other firms.

The contractor also designated two BIM managers on the project to lead the $4 \mathrm{D}$ and the $5 \mathrm{D}$ aspects. 


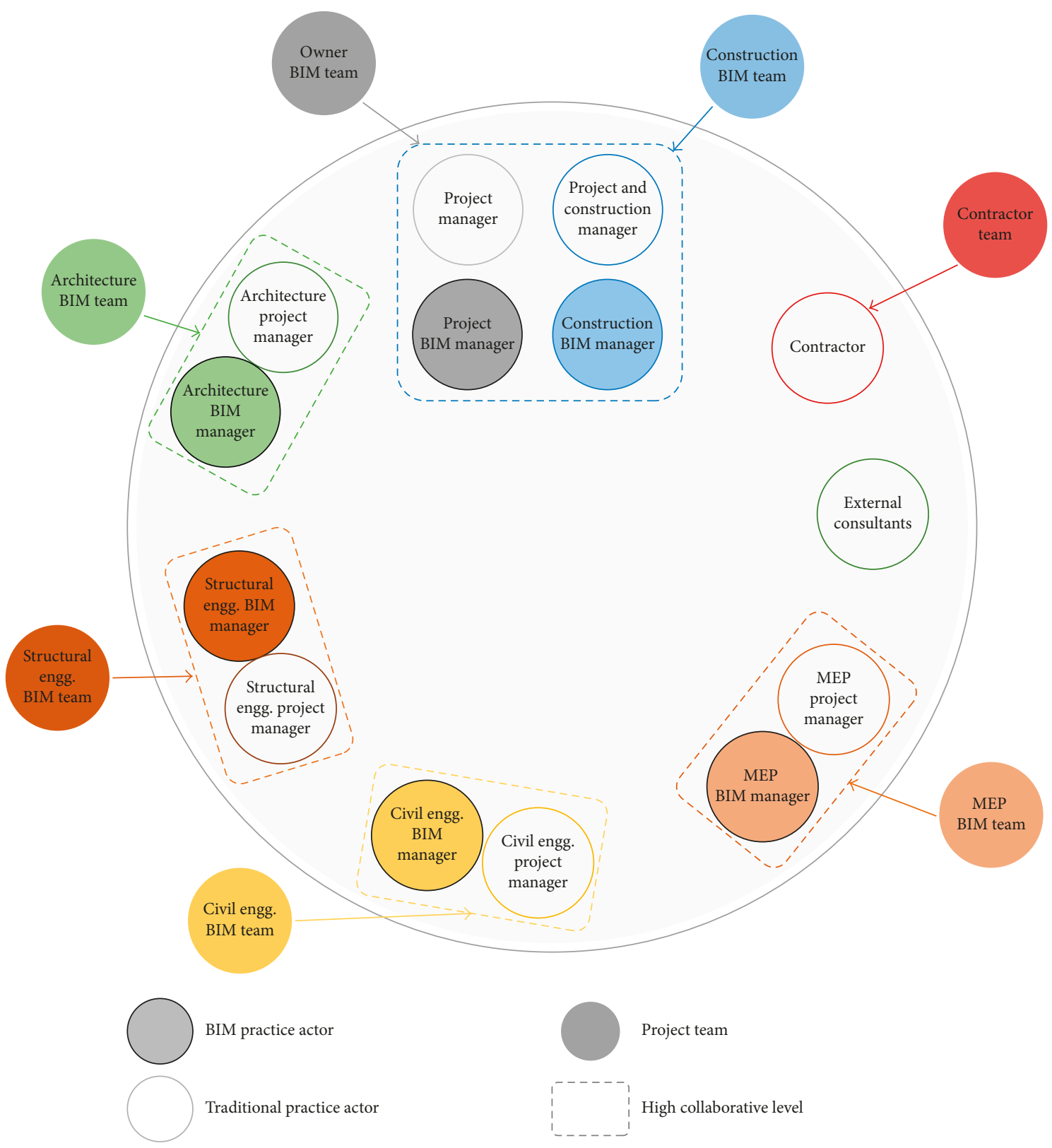

Figure 3: Managerial roles in the project (source: Project documentation).

The case study shows a crystallization of the information subprocess around the BIM managers, creating two separate leadership poles in the project. The first is related to the project plan embodied by the project manager. It is based on the management of the project activities according to the work breakdown structure (WBS). The second management system, related to the BIM execution plan, is embodied by the BIM manager and is mainly based on the management of the project information. As a result, while the BIM managers focus on the model-based information flow, the project managers do not seem comfortable with the model and focus on the work and the material flow. "The project manager is mainly responsible for submitting the documents and focuses on the percentage of completion of the work [...] He never got involved in 3D coordination," says a MEP team member. The project BIM manager is more precise: "Due to the lack of BIM knowledge and processes by the construction manager, he was unable to manage his teams in accordance with the workflow required for BIM. [...] He also did not know when he had to call on me to advise him in the proper distribution of BIM roles and tasks to his staff," he says.

4.2. As-Planned versus Actual Processes. As stated above, unlike current project management practices, the preparation of a BIM execution plan (BEP) is collaborative. BIM managers act as facilitators and coach to help the team develop a shared plan and to elaborate the strategy for the production of the models in the course of the project. 
The plan is then supposed to be fully reliable, and the proposed processes are expected to be close to those that will be implemented.

Regarding the BIM execution plan provided at the beginning of the project, the respondents do not have any entrenched position. Overall, one-fourth of them clearly think that the recommended processes are not precise and detailed enough and the same proportion think the opposite. The other half seems to have a strict neutral position. The processes detailed in the BIM execution plan were not strictly applied. Instead, they were seen more as guidelines to allow the practitioners to be guided in their actual work. It is "difficult [to apply the proposed processes] because we finally are only doing a modeling job instead of a production job," commented a practitioner whose firm did not implement BIM before this project. Note that no one indicated they used their own processes, rather than those in the BIM execution plan but some deviations can be observed.

The opinions of the respondents differ about the gap between the processes in the BIM execution plan (and other project documentation) and the actual ones. On a ranking scale of 1 (no deviation) to 10 (very strong deviation), fifty percent of them note "only a very few deviations," while the same proportion indicates there were average and significant deviations." To better understand the gaps between the processes in the BIM execution plan (and other project documentation) and the actual ones deployed, it is helpful to study how the different processes are perceived by the practitioners. Three main groups of processes were used in the project: information exchange and synchronization processes, 3D coordination and interference detection processes, and quality control processes. The deviation is perceived as average for the three groups of processes. However, while the proportion of people who indicate that the processes used totally comply with those recommended in the BIM execution plan is the same for the three different groups of processes, and it appears that gaps are considered to be less important for synchronization processes $(25 \%$ chose "Low gap" instead of $12.5 \%$ for the other processes).

During the semidirected interviews, all the interviewed participants believed that the processes recommended by the execution plan were too theoretical and too general and were not adapted to the project. "The processes in the BIM execution plan remain very theoretical, and there are not a large number of people who use these documents to work on a daily basis, despite the fact that the recommended processes show the main principles of the project," said a BIM manager. In general, the proposed processes are seen as difficult to apply and not close enough to the project's reality. It should be mentioned that even if it was claimed that the execution plan was inspired by the Pennsylvania State BIM Project Execution Guide, the proposed processes are not described using the Pennsylvania State formalism. The formalism used was also not the BPMN advocated by the Building Smart alliance. "It is a great effort to have outlined the processes to follow but they are natural and too obvious. [...] Ideally, it would have been useful to show the information requirements at some given moments. Here, nothing is detailed enough," said a BIM manager. Beyond the formalization issues, one of the main criticisms practitioners made about the execution plan is that it does not take into account the particular need in a fast-track project for different disciplines to coordinate with each other. "We tried to apply the processes proposed in the BIM execution plan. But the fast track project is not linear," noted a BIM coordinator. Actually the structural engineering firm had to issue its first outcomes very quickly, before the other firms, while taking into account the evolution of the architectural and the MEP models. In collaboration with the other stakeholders, it has finally been decided that deadlines would be applied to MEP engineers and architects only on the parts of the model required to produce the structural models. On this subject, the study has noted some particular needs for coordination between the architects and the structure, for which the two firms have adopted the exchange of manuscript sketches. These sketches represent a quick and efficient way to convey valuable information from architects to the structure firm so that it can adapt its models and deliver its deliverables on time and with the required quality. "Architects make large use of this medium to quickly communicate their ideas. We can then update our model based on these sketches; it is a fast and effective way to transmit last minute information when it is necessary," said the BIM manager of the structural engineering firm.

Moreover, issues related to the quality control processes were noted by multiple practitioners. For the structural engineering firm, too many quality control processes were described in the execution plan that were not adapted to their situation. They believe that an effective quality control as described would take three full weeks, which is totally unthinkable with such a fast-track project where the models were continually evolving. The participants adopted the collective idea of advancing the models and performing interference detection at planned moments when the appropriate elements had been modeled properly. Another aspect of quality control is related to the contractor who, according to the execution plan process, had the responsibility to audit the models and their compliance to the Uniformat standard. This process, planned to be managed by the contractor, raised some contractual liability questions. While it was not possible to validate these assertions during the observation period, some stakeholders believed that BIM managers should be responsible for interdisciplinary quality control.

4.3. The Use of a Common Physical Space. One interesting particularity of this project lies in the fact that all of the project team members had to share a common physical space provided by the business managing firm near the construction site. The idea here is similar to the "Big Room" concept and is designed to collaboration synergies among disciplines. One of the study's goals is to understand how the respondents perceive the impact and the potential difficulties emerging from working in a common space with other disciplines on the project's efficiency. The unclear contract clause regarding such open space work was perceived as having a significant impact by the respondents. Indeed, 
compared to a traditional project configuration, working in the same physical space during a project seems to have a very positive impact on communication, collaboration, and trust between stakeholders, and on information and data exchange. "The project office focused on this specific project. No other project is likely to monopolize our minds. Here, all the teams are mobilized for this one project," said a BIM coordinator. "The common space is very useful. It brings together the owner and the other disciplines. It serves as an integrator, information is better shared. Small succinct meetings are very effective," added the project manager. This physical proximity contributes to a common synergy, the feeling of working around a goal common to all, simplifies the design phase, increases the effectiveness of decisionmaking, and contributes to the understanding of a project's specific BIM processes. "At the preliminary stage, there is about one BIM meeting per month. It seems sufficient, given that the workspace is conducive to speaking directly with the people concerned in case of problems," a BIM manager said. Another BIM manager added "We have a great advantage in being in a common physical space. This provides quick solutions. There is no loss of time or information when interacting with other professionals." Moreover, a very large proportion of the respondents felt very positive about their desire to work in such colocation configurations in future projects.

\section{Conclusion}

Based on an exploratory case study, this paper explored the practitioners' perception of the BIM and project management practices. It then discussed the evolution of the roles of the BIM specialists, how the information subprocess is being crystallized around the BIM manager, and the reliability of the proposed BIM processes for effective collaboration. It raised some hypotheses that deserve to be investigated in future works. The first hypothesis is related to the new roles a BIM project requires, including that of the BIM manager. The project manager seems to no longer be the single central actor of the project; the BIM manager seems to now appear and to act as a new major player, with some managerial responsibilities. The possible crystallization of the information subprocess around the BIM managers reveals the importance of information management in BIM projects and how it is necessary to clearly redefine the connections and the interactions between the workflow and the information flow. It seems that the information-centered approach proposed by Winch [14] for the management of construction projects could be very helpful in the future. The last hypothesis is related to the ability of the current BIM processes (advocated in BIM execution plans or guidelines) to successfully support the use of BIM in construction projects. These processes appear to be too generic and do not really take into account all the complexity of the construction industry dynamics.

Compared to the recent relevant similar case studies presented in the literature review section, this study provides a new perspective of the professionals' perception of BIM projects and proposes new hypothesis to investigate. But some inevitable limitations and interrogations remain, mainly due to the exploratory nature of the case study. As state in Section 3, the exploratory case study can be considered as a sensible and sound first step, which main aim is not to generate definitive conclusion but to suggest hypotheses to be checked later. The flexible structured form of the conclusions can then be read in this perspective. Regarding the survey, it would have been interesting to have more respondents but despite our efforts, only a limited number of practitioners were available for the survey and the interviews.

Future works will focus on investigating the hypotheses, with a particular emphasis on how systemic theories could complement the current approaches in improving the current BIM processes for a more successful collaboration.

\section{Data Availability}

The data used to support the findings of this study are available from the corresponding author upon request.

\section{Conflicts of Interest}

The authors declare that they have no conflicts of interest.

\section{References}

[1] C. Boton and D. Forgues, "The need for a new systemic approach to study collaboration in the construction industry," Procedia Engineering, vol. 196, pp. 1043-1050, 2017.

[2] O. A. Olatunji, "Modelling organizations' structural adjustment to BIM adoption: a pilot study on estimating organizations," Electronic Journal of Information Technology in Construction, vol. 16, pp. 652-668, 2011.

[3] B. Hardin and D. McCool, BIM and Construction Management: Proven Tools, Methods, and Workflows, John Wiley \& Sons, Hoboken, NJ, USA, 2015.

[4] T. Hartmann, H. Van Meerveld, N. Vossebeld, and A. Adriaanse, "Aligning building information model tools and construction management methods," Automation in Construction, vol. 22, pp. 605-613, 2012.

[5] M. Fischer, A. Khanzode, D. Reed, and H. W. Ashcraft, Integrating Project Delivery, John Wiley \& Sons, Hoboken, NJ, USA, 2017.

[6] E. Papadonikolaki, R. Vrijhoef, and H. Wamelink, "The interdependences of BIM and supply chain partnering: empirical explorations," Architectural Engineering and Design Management, vol. 12, no. 6, pp. 476-494, 2016.

[7] H. Li and T. Hartmann, "Computing advances applied for building design, operation, retrofit and supply chain information processing," Advanced Engineering Informatics, vol. 31, p. 1, 2017.

[8] S. J. Wilkinson and J. R. Jupp, "Exploring the value of BIM for corporate real estate," Journal of Corporate Real Estate, vol. 18, pp. $254-269,2016$.

[9] J. Won and J. C. P. Cheng, "Identifying potential opportunities of building information modeling for construction and demolition waste management and minimization," Automation in Construction, vol. 79, no. 3, pp. 3-18, 2017.

[10] J. M. Kamara, C. J. Anumba, and N. F. O. Evbuomwan, Capturing Client Requirements in Construction Projects, Thomas Telford, London, UK, 2002. 
[11] B. Becerik-Gerber, F. Jazizadeh, N. Li, and G. Calis, "Application areas and data requirements for bim-enabled facilities management," Journal of Construction Engineering and Management, vol. 138, pp. 431-442, 2012.

[12] M. P. Tucker, M. R. A. Masuri, and A. Cotgrave, "Critical strategic issues for the integration of facilities management into the development process," Property Management, vol. 35, no. 4, pp. 380-393, 2017.

[13] H. B. Cavka, S. Staub-French, and E. A. Poirier, "Developing owner information requirements for BIM-enabled project delivery and asset management," Automation in Construction, vol. 83, pp. 169-183, 2017.

[14] G. M. Winch, Managing Construction Projects: An Information Processing Approach, Blackwell Publishing, Hoboken, NJ, USA, 2nd edition, 2010.

[15] C. Eastman, P. Teicholz, R. Sacks, and K. Liston, BIM Handbook: A Guide to Building Information Modeling for Owners, Managers, Designers, Engineers and Contractors, John Wiley \& Sons, Hoboken, NJ, USA, 2011.

[16] H. Kerosuo, T. Mäki, and J. Korpela, "Knotworking-a novel BIM-based collaboration practice in building design projects," in Proceedings of 5th International Conference on Construction Engineering and Project Management ICCEPM, pp. 1-7, Anaheim, CA, USA, January 2013.

[17] A. Khanzode, M. Fischer, D. Reed, and G. Ballard, A Guide to Applying the Principles of Virtual Design \& Construction (VDC) to the Lean Project Delivery Process, Stanford University, Stanford, CA, USA, 2006.

[18] R. Vrijhoef and L. Koskela, "The four roles of supply chain management in construction," European Journal of Purchasing \& Supply Management, vol. 6, no. 3-4, pp. 169-178, 2000.

[19] B.-C. Björk, "Information technology in constructiondomain definition and research issues," International Journal of Computer Integrated Design And Construction, vol. 1, pp. 1-16, 1999.

[20] J. Mélèse, Approches Systémiques Des Organisations: Vers l'Entreprise à Complexité Humaine: Les Editions d'Organisation, 1990.

[21] H. Howard, R. Levitt, B. C. Paulson, J. G. Pohl, and C. B. Tatum, "Computer integration: reducing fragmentation in AEC industry," Journal of Computing in Civil Engineering, vol. 3, pp. 18-32, 1989.

[22] H. Voordijk and R. Vrijhoef, "Improving supply chain management in construction: what can be learned from the aerospace industry?" in Proceedings of 19th Annual ARCOM Conference, vol. 2, pp. 3-5, Brighton, UK, 2003.

[23] G. Winch, "Zephyrs of creative destruction: understanding the management of innovation in construction," Building Research \& Information, vol. 26, no. 5, pp. 268-279, 1998.

[24] J. Beetz, "Facilitating distributed collaboration in the AEC/FM sector using Semantic Web Technologies," 2009, http:// alexandria.tue.nl/extra2/200911977.pdf.

[25] A. O. AlSehaimi, P. Tzortzopoulos Fazenda, and L. Koskela, "Improving construction management practice with the last planner system: a case study, engineering," Construction and Architectural Management, vol. 21, no. 1, pp. 51-64, 2014.

[26] M. Shelbourn, N. M. Bouchlaghem, C. Anumba, and P. Carrillo, "Planning and implementation of effective collaboration in construction projects," Construction Innovation, vol. 7, no. 4, pp. 357-377, 2007.

[27] E. Poirier, D. Forgues, and S. Staub-French, "Collaboration through innovation: implications for expertise in the AEC sector," Construction Management and Economics, vol. 34, no. 11, pp. 769-789, 2016.
[28] E. A. Poirier, D. Forgues, and S. Staub-French, "Understanding the impact of BIM on collaboration: a Canadian case study," Building Research and Information, vol. 45, no. 6, pp. 681-695, 2017.

[29] Y. Liu, S. van Nederveen, and M. Hertogh, "Understanding effects of BIM on collaborative design and construction: an empirical study in China," International Journal of Project Management, vol. 35, no. 4, pp. 686-698, 2017.

[30] G. Mignone, M. R. Hosseini, N. Chileshe, and M. Arashpour, "Enhancing collaboration in BIM-based construction networks through organisational discontinuity theory: a case study of the new Royal Adelaide Hospital," Architectural Engineering and Design Management, vol. 12, no. 5, pp. 333-352, 2016.

[31] S. Kim, D. Ph, S. Chin et al., "Measurement of construction BIM value based on a case study of a large-scale building project," Journal of Management in Engineering, vol. 33, no. 6, pp. 1-10, 2017.

[32] C. Merschbrock and B. E. Munkvold, "Effective digital collaboration in the construction industry-a case study of BIM deployment in a hospital construction project," Computers in Industry, vol. 73, pp. 1-7, 2015.

[33] D. Holzer, The BIM Manager's Handbook: Guidance for Professionals in Architecture, Engineering, and Construction. Best Practice BIM ePart 1, Wiley, Hoboken, NJ, USA, 2015.

[34] R. Eadie, M. Browne, H. Odeyinka, C. McKeown, and S. McNiff, "BIM implementation throughout the UK construction project lifecycle: an analysis," Automation in Construction, vol. 36, pp. 145-151, 2013.

[35] M. de Blois, G. Lizarralde, and P. De Coninck, "Iterative project processes within temporary multi-organizations in construction: the self-, eco-, re-organizing projects," Project Management Journal, vol. 47, pp. 27-44, 2016.

[36] J. L. Fernández-Solís, "The systemic nature of the construction industry," Architectural Engineering and Design Management, vol. 4, no. 1, pp. 31-46, 2008.

[37] L. Forbes and H. Ahmed, Modern Construction: Lean Project Deliver and Integrated Practices, CRC Press, Boca Raton, FL, USA, ISBN 9781420063127, 2010.

[38] B. Jones, "Integrated project delivery (IPD) for maximizing design and construction considerations regarding sustainability," Procedia Engineering, vol. 95, pp. 528-538, 2014.

[39] L. Crawford, Profiling the Competent Project Manager, University of Technology, Sydney, NSW, Australia, 2000.

[40] A. Munns and B. Bjeirmi, "The role of project management in achieving project success,", International Journal of Project Management, vol. 14, no. 2, pp. 81-87, 1996.

[41] H. R. Kerzner, Project Management: a Systems Approach to Planning, Scheduling, and Controlling, John Wiley \& Sons, Hoboken, NJ, USA, 2013.

[42] W. P. Cooper, "The project manager toolkit," Engineering Management Journal, vol. 1, no. 1, p. 27, 1991.

[43] X. Meng and P. Boyd, "The role of the project manager in relationship management," International Journal of Project Management, vol. 35, no. 5, pp. 717-728, 2017.

[44] P. R. Lawrence and J. W. Lorsch, "New management job: the integrator," Army Organizational Effectiveness Journal, vol. 4, pp. 27-34, 1984.

[45] Project Management Institute, A Guide to the Project Management Body of Knowledge (PMBOK Guide), Project Management Institute, Newtown Square, PA, USA, 5th edition, 2013.

[46] The Computer Integrated Construction Reseaerch Program, Building Information Modeling Execution Planning Guide, 
Computer Integrated Construction Research Group, The Pennsylvania State University, State College, PA, USA, 2010.

[47] United States Air Force, Building Information Modeling Project Execution Plan (PxP): Version 2.1, United States Air Force, Washington, DC, USA, 2015.

[48] D. Holzer, The BIM Manager's Handbook: Guidance for Professionals in Architecture, Engineering, and Construction. Change Management ePart 2, Wiley, Hoboken, NJ, USA, 2015.

[49] K. Davies, S. Wilkinson, and D. McMeel, "A review of specialist role definition in BIM guides and standards," Electronic Journal of Information Technology in Construction, vol. 22, pp. 185-203, 2017.

[50] T. M. Froese, "The impact of emerging information technology on project management for construction,", Automation in Construction, vol. 19, no. 5, pp. 531-538, 2010.

[51] D. Bryde, M. Broquetas, and J. M. Volm, "The project benefits of building information modelling (BIM)," International Journal of Project Management, vol. 31, no. 7, pp. 971-980, 2013.

[52] M. Day, "BIM is not CAD, AEC Magazine," 2013, http:// aecmag.com/technology-mainmenu-35/531-bim-is-not-cad.

[53] M. B. Barison and E. T. Santos, "An overview of BIM specialists roles and responsibilities of BIM Specialists," in Proceedings of International Conference on Computing in Civil Engineering, Nottingham, UK, June-July 2010.

[54] C. Boton, D. Forgues, and G. Halin, "A framework for Building Information Modeling implementation in engineering education," Canadian Journal of Civil Engineering, 2018.

[55] J. Gerring, "What is a case study and what is it good for?," American Political Science Review, vol. 98, pp. 341-354, 2004.

[56] R. K. Yin, Case Study Research: Design and Methods, SAGE Publications, Newbury Park, CA, USA, 2nd edition, 1994.

[57] K. M. Eisenhardt, "Building theories from case study research," Academy of Management Review, vol. 14, pp. 532550, 1989.

[58] R. K. Yin, “The case study crisis: some answers*," Administrative Science Quarterly, vol. 26, pp. 58-65, 1981.

[59] R. K. Yin, Case Study Research: Design and Methods, SAGE Publications, Newbury Park, CA, USA, 5th edition, 2013.

[60] R. T. Ogawa and B. Malen, "Towards rigor in reviews of multivocal literatures: applying the exploratory case study method," Review of Educational Research, vol. 61, no. 3, pp. 265-286, 1991.

[61] L. Letrilliart, I. Bourgeois, A. Vega, J. Cittée, and M. Lutsman, "Un glossaire d'initiation à la recherche qualitative, exercer," La Revue Française de Médecine Générale, vol. 20, pp. 106112, 2009.

[62] T. Hartmann, M. Fischer, and J. Haymaker, "Implementing information systems with project teams using ethnographicaction research," Advanced Engineering Informatics, vol. 23, no. 1, pp. 57-67, 2009.

[63] Computer Integrated Construction Research Program, BIM Planning Guide for Facility Owners, Computer Integrated Construction, University Park, PA, USA, 2012.

[64] G. V. Williams, "Fast track pros and cons: considerations for industrial projects," Journal of Management in Engineering, vol. 11, no. 5, pp. 24-32, 1995. 


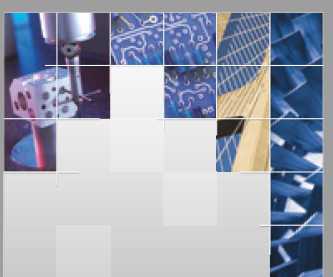

\section{Enfincering}
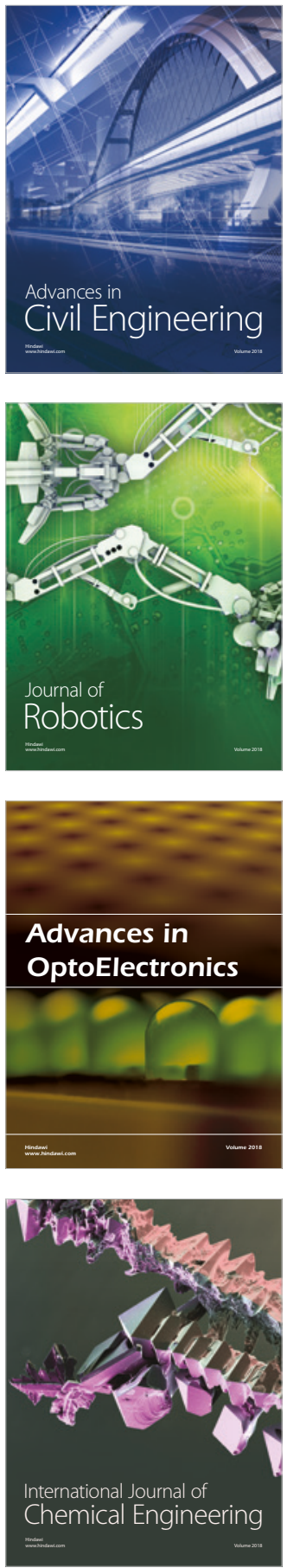

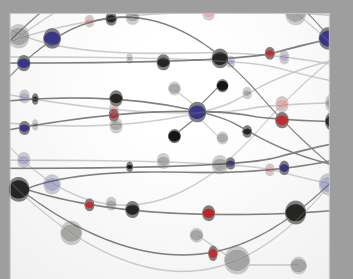

\section{Rotating \\ Machinery}

The Scientific World Journal

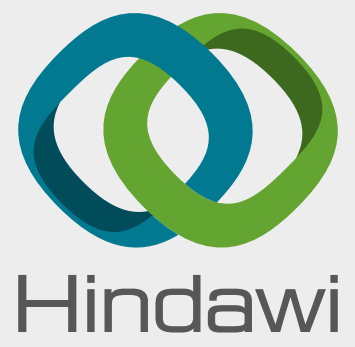

Submit your manuscripts at

www.hindawi.com
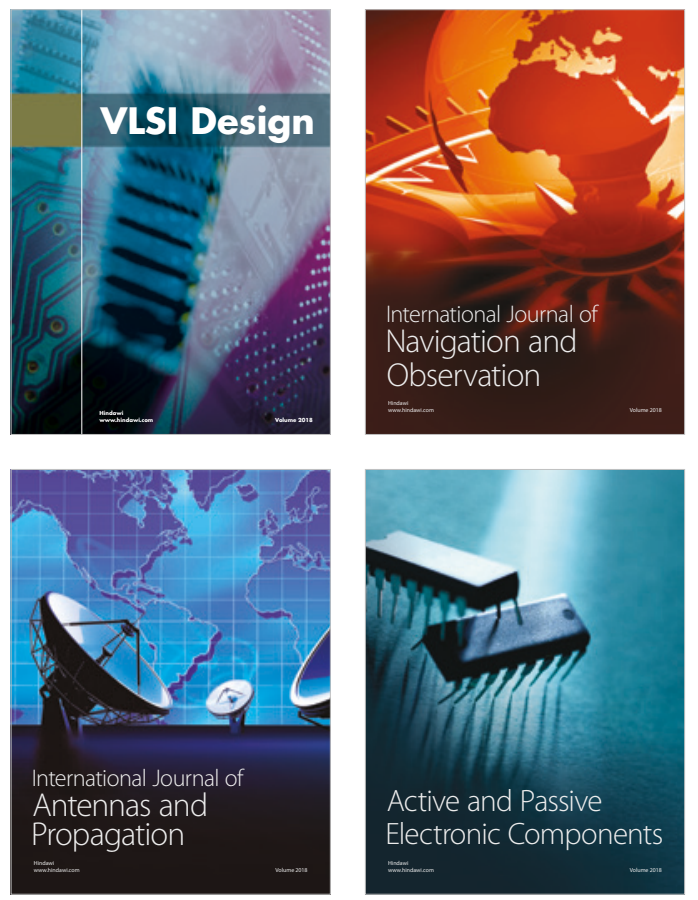
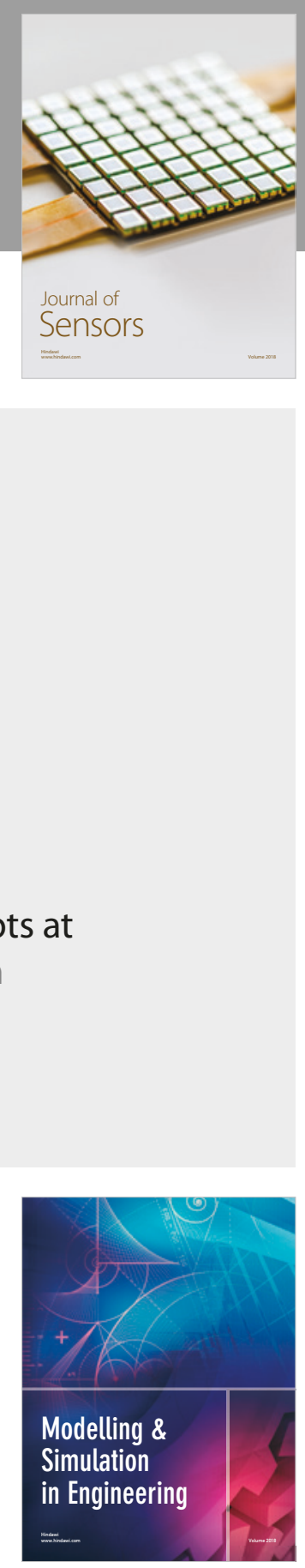

\section{Advances \\ Multimedia}
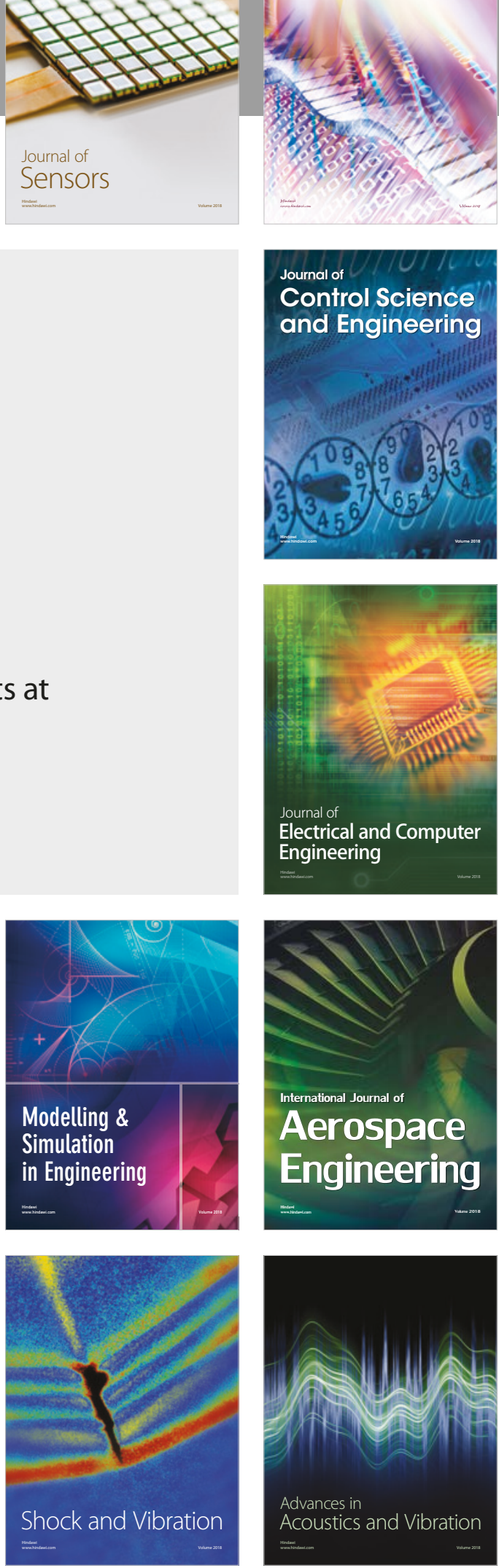